\title{
Logical model of a behavior change program for community intervention - Active Life Improving Health - VAMOS
}

\author{
Modelo Lógico do programa Vida Ativa Melhorando a Saúde - VAMOS
}

Tânia Rosane Bertoldo Benedetti', Sofia Wolker Manta', Luiz Salomão Ribas Gomez', Cassiano Ricardo Rech

\begin{abstract}
The present study aimed to present a Logic Model (LM) of the "Vida Ativa Melhorando a Saúde" (VAMOS - Active Life Improving Health) program for its application in community interventions in adults and old age in Brazil. The VAMOS program purpose is to motivate people to have a healthier lifestyle. It is divided in 12 group meetings usually held weekly, varying from three to five months of duration. VAMOS is guided by specific booklets and conducted by health professionals with prior certification. The LM consists of activities (advertising, meetings, community outreach), products (financial resources, promotion, increase in attendance) and short, medium and long term objectives (adoption of the program, knowledge and empowerment of participants). Participants of the VAMOS program maintained their physical activity levels for longer when compared with traditional and control groups. VAMOS is under expansion in Brazil, supporting behavior changes in order to reach a healthier lifestyle.
\end{abstract}

\section{Keywords}

Logic model; Physical activity; Healthy eating; Behavior change.

\section{Resumo}

O objetivo deste estudo foi apresentar o Modelo Lógico (ML) do programa Vida Ativa Melhorando a Saúde (VAMOS) para sua aplicação em intervenções comunitárias em adultos e idosos com o objetivo de motivá-los a adotarem um estilo de vida saudável. $O$ VAMOS é desenvolvido em 12 encontros presenciais, com apoio de livretos, ocorrendo uma vez por semana, com duração prevista de três a cinco meses econduzido por profissionais certificados. No $M L$ estão presentes as atividades realizadas (publicidade, reuniões, alcance), os produtos (recursos financeiros, divulgação) e objetivos em curto, médio e longo prazos (adoção do programa, conhecimento e autonomia para um estilo de vida ativo). Os participantes do VAMOS têm mantido os níveis de atividade física por mais tempo quando comparados aos do grupo de exercícios físicos e de controle. O VAMOS está em expansão no país favorecendo mudanças de comportamento em busca de um estilo de vida mais saudável.

\section{Palavras-chave}

Modelo lógico; Atividade física; Alimentação saudável; Mudança de comportamento.

\section{Introduction}

The National Policy on Health Promotion recommends the implementation of programs/actions that promote a healthy lifestyle for the Brazilian population ${ }^{1}$. However, there are still barriers, such as those associated with the lack of human, structural and financial resources for the expansion of programs on health promotion ${ }^{2}$. Additionally, some of the actions developed, especially in primary care, have focused on specific groups and little is known about how the contents, goals and objectives of such programs/ actions are structured and organized. In this sense,

1 Federal University of Santa Catarina, Sports Center, Florianópolis, Santa Catarina, Brazil. managers have used a basic tool for the development and implementation of programs/actions for the structuring of the Logic Model (LM).

The LM is a useful tool that allows the relationships between the required resources, interventions (planned actions) and effects (products, results and impacts) aimed to be reached through the program in a visual and systematic way ${ }^{3}$. One of the main advantages of developing a LM is the possibility of communicating the purpose of the program.

In Florianopolis, in 2012, there was a proposal for community intervention - Vida Ativa Melhorando a Saúde (VAMOS - Active Life Improving Health), aimed at promoting healthy lifestyles, particularly including a reduction in physical inactivity and the 
adoption of an adequate and healthy diet ${ }^{4}$.

VAMOS is based on the concept of empowerment, following an approach towards the improvement of individual abilities and seeking to identify the barriers that are important and relevant for the life of individuals and to develop strategies to resolve/minimize them.

The LM of the VAMOS program contributes to its dissemination in other country regions, increasing the reach of health promotion actions in Brazil. Thus, the present study aimed to show a logic model for the VAMOS program, so that it can be applied to community interventions in adults and old age in Brazil.

\section{The creation of the VAMOS program}

The creation of the VAMOS program was based on discussions about physical activity (PA) strategies provided in Brazil, which thus far had been primarily offered through programs that used the traditional model, depending on a teacher who gives specific classes (gymnastics, walking etc.) and on a low number of participants (around 30 individuals per class) and lasting approximately one hour, two to three times a week ${ }^{4}$. This program method has a low reach and high costs.

Based on discussions with Brazilian and American researchers and following the "Active Living Every Day" (ALED) ${ }^{6}$, VAMOS was created. This program has been improved since 2011 as a way to contribute to behavior changes.

In 2012, the first version of the program showed a positive effect on the increase in low-intensity PA in old age ${ }^{4}$. Based on this experience, there was the need to include topics on eating habits and participation of adults. Moreover, other changes were made to the printed materials, such as: the increase in font size in the texts; the change of the type of paper from couches to matt; the adaptation/inclusion of images and photographs, the division of the material into several booklets; and adjustments of examples to the Brazilian reality ${ }^{7}$. Additionally, designers also contributed to the improvements, when the name of the program was adopted, "Vida Ativa Melhorando a Saúde” (VAMOS - Active Life Improving Health) Program. The Logic Model (LM) was subsequently developed for this purpose.

VAMOS activities are founded on the socio-cognitive theory, where human beings are not passive beings, but rather dependant on environmental actions and influencing all processes ${ }^{8}$. In this sense, such program is expected to encourage participants to understand what their self-perception of specific types of behavior is, such as PA and adequate and healthy eating habits.

\section{Development of the logic model for the VAMOS program}

The LM has been recommended as a way to evaluate programs ${ }^{3-9}$. It is a tool that enables the description of actions in relation to resources, influencing factors, activities and products provided, the results expected and obtained (in the short, medium and long-term) and program objectives ${ }^{3}$. Aiming to create the LM, a team of Brazilian and foreign researchers comprised of Physical Education, Nutrition, Public Health and Design professionals, city managers, health professionals working in Health Centers, community participants and community health agents were interviewed and/or participated in the creation process and/or focus groups.

\section{The process of implementation and evaluation of the VAMOS program}

Based on the creation of the LM, the present study was sent to the City Department of Health, approved and subsequently sent to the Research Ethics Committee of the Federal University of Santa Catarina (process number 480560; 2387/2010). 
This program is developed through 12 in-person meetings and presented in booklets. The first one includes an introduction, while the other 11 meetings deal with contents comprising outcomes of behavioral change (PA and eating habits) and a booklet with the appendix. At each meeting, the contents and activities are aimed at helping participants to understand the need to make behavioral changes regarding PA and adequate and healthy eating habits, in addition to promoting and maintaining them. The titles and objectives of each meeting are shown in Table 1 .

TABLE 1 - Presentation of the objectives of each VAMOS Program meeting. Florianópolis, Brazil, 2015.

\section{1st Meeting - Introduction \\ To present the program and educational material. \\ To pre time to change inactivity into physical activity, understand different physical ac tivity levels, prepare a physical activity plan and self-monitor one's practice}

To record the changes already made, to understand concepts of physical activity, physical exercise and healthy eating habits, to identify one's willingness to change and the benefits of a healthy life.

4th Meeting - Let's decide and practice? 5th Meeting - Let's overcome challenges? To reflect how one spends one's time, how to find To identify the obstacles to healthy eating habits

\section{7th Meeting - Let's obtain support and go step} by step?

To identify the main sources of support of each one, to review the physical activity plan and to present the pedometer as a self-monitoring strategy.

10th Meeting - Let's reduce stress?

To identify stressful situations and to learn techniques to reduce stress and ways to manage time. and a more active life and to reflect on solutions. 8th Meeting - Let's become more confident and review the goals?

To assess progress, to reestablish new goals for eating habits, to raise awareness of the importance of trusting one's actions, always having positive messages in mind and the role of stretching exercises.

11th Meeting - Let's find out new opportunities to have a healthy life? To identify new options to be physically active, to have healthier eating habits and to make healthy choices last longer. 3rd Meeting - Let's find out more about healthy eating habits?

To increase knowledge about what healthy eating habits are and how this can become part of one's routine.

6th Meeting - Let's establish goals?

To establish goals, to plan monitoring and to have positive messages in mind. 9th Meeting - Let's face the obstacles? To identify and recognize obstacles to behavioral changes and to raise awareness of the importance of preparing oneself for risk situations and the role of muscle-strengthening activities.

12th Meeting - Let's make lasting changes? To celebrate the achievements made, to identify strategies that work for each one, to reflect on ways to solve problems and to make the commitment of maintaining new types of behavior.

\section{The product of LM}

LM includes short, medium and long-term objectives, in addition to the products and activities to be developed (Figure 1).

\section{Consultants \\ Brazilian \\ researchers \\ Foreign \\ researchers \\ Managers \\ Health \\ professionals \\ Community \\ agents \\ Team, \\ support}

\section{Beginning}
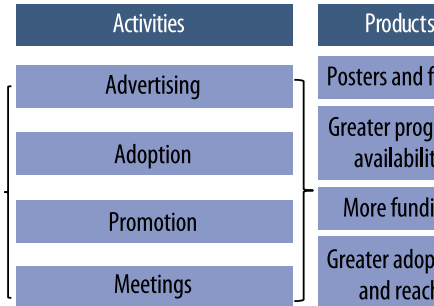

Posters and flyers

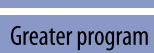

availability

Contractors
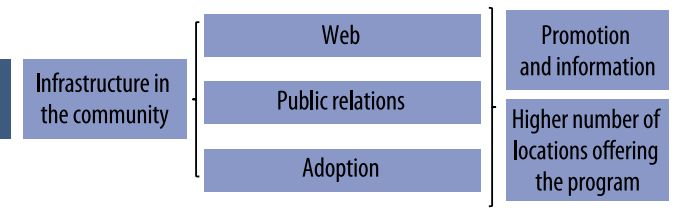

Research

and evaluation

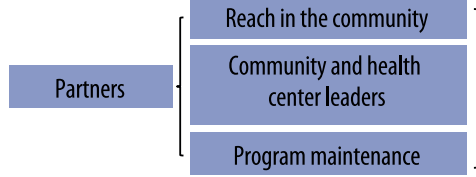

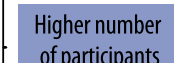

of participants
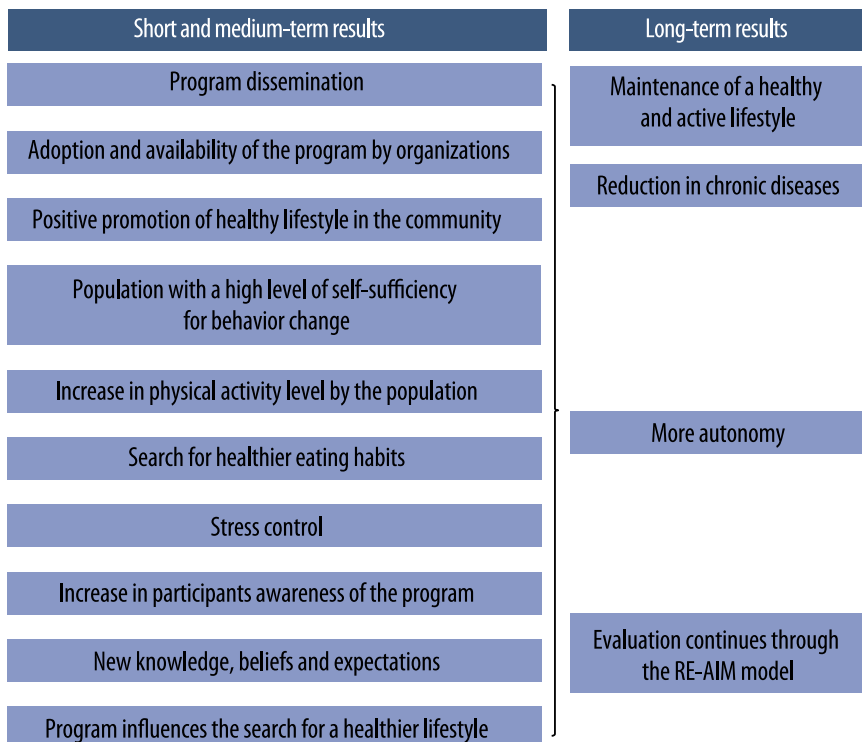

More autonomy

Evaluation continues through the RE-AIM model

FIGURE 1 - Logic Model of the VAMOS Program - Active Life Improving Health. Florianopolis, Brazil, 2015. 


\section{Program objectives}

In the short term, the objective of VAMOS is centered on enabling organizations and group to raise awareness, adopt and disseminate the program. In the medium term, knowledge, beliefs and expectations are disseminated so that a higher number of adults and old age participate in this program, seeking a healthier lifestyle. Finally, in the long term, adults and old age should have more autonomy for these choices and chronic diseases should have been reduced.

\section{Areas of action of the program and population}

The VAMOS program was designed for adults (aged more than 18 years) and old age of both sexes, with any level of education and from different Brazilian regions. It can be adapted according to the reality of each region/location/culture. It should be preferably applied to individuals who are insufficiently active and/or have inadequate and unhealthy eating habits.

The VAMOS program can be offered by any health professionals with higher education, provided that they receive specific training with certification. This training is based on distance learning, lasting approximately 20 hours and including a certification test that requires at least 80/100 for approval (www.vamos.ufsc.br).

The activities developed in the program begin with the formation of the team who will participate and be responsible for the different actions required, from its promotion to evaluation. Aiming to achieve the short, medium and long-term goals, individuals must be committed and able to promote the program wherever possible. Additionally, raising the team's awareness is an important strategy to broaden its reach in the community.

This program is implemented during meetings lasting from one to two hours per week, between three and five months. Up until now, VAMOS has been offered in the Health Centers of the city of Florianopolis, in the health gym of Belo Horizonte and in the University Hospital of Recife. This program costs approximately R\$150.00 (US\$ 50.00) per person/course, including the distribution of educational materials (booklets) and a pedometer that acts as a motivational factor for self-monitoring of physical activity levels (this equipment is distributed during the $6^{\text {th }}$ meeting).

Thus, the VAMOS program is still expanding in Brazil and training through distance learning is under construction. The Federal University of Santa Catarina (UFSC) plays a major role in the creation and validation of this program for the community and, in this sense, also contributes to the renewal of programs on changes in health behavior to meet the actual needs of the Brazilian population.

\section{Acknowledgements/Funding:}

The present study was funded by the "Conselho Nacional de Desenvolvimento Científico e Tecnológico" (CNPq - National Council for Scientific and Technological Development - General Public Notice 14/2012. Process number 475.075/2012) and "Fundação de Amparo à Pesquisa e Inovação do Estado de Santa Catarina” (FAPESC - Santa Catarina State Research and Innovation Support Foundation), "Programa Pesquisa para o SUS (PPSUS - Research Program for the Unified Health System)" process number 2014TR2263.

Os autores declaram não haver nenhum tipo de conflito de interesse na elaboração do estudo.

\section{Author contributions:}

T.R.B. Benedetti (0000-0002-2035-5082) was responsible for the creation of the 
VAMOS Project and critical review of the intellectual content of the present article. S.W. Manta (0000-0002-1059-2471) helped with the data analysis and interpretation and article writing. L.S.R. Gomes (0000-0001-8205-9548) was responsible for the graphic design of the VAMOS Project and critical review of the intellectual content of the present article. C.R. Rech (0000-0002-9647-3448) participated in the construction and validation of the logic model and article writing and review.

\section{References}

1. Brazil. National Policy on Health Promotion, Revision of Decree MS/GM n ${ }^{\circ} 687$ from March 30th 2006. Ministry of Health. Brasília, DF. Brazil, 2014. Available in: http:// bvsms.saude.gov.br/bvs/publicacoes/pnps_revisao_portaria_687.pdf. Accessed in: $10 / 5 / 2015$.

2. Amorim TC, Knuth AG, Cruz DKA, Malta DC, Reis RS, Hallal PC. Description of city programs of physical activity promotion funded by the Ministry of Health. Rev Bras Ativ Fis Saúde. 2013;18(1):63-74.

3. U. S. Departament of Health and Human Services. Centers for Disease Controle and Prevention (CDC). Physical Activity Evaluation Handebook. Atlanta, Georgia, GA. United States of America, 2002. Available in: https://www.cdc.gov/nccdphp/dnpa/ physical/handbook/pdf/handbook.pdf Accessed in: 10/5/2015.

4. Benedetti TRB, Schwingel A, Gomez LSR, Chodzko-Zajko W. "VAMOS" Program (Active Life Improving Health): from conception to initial results. Rev Brasil Cineant Desemp Hum. 2012;14(6):723-37.

5. Brazil. Surveillance of Risk and Protective Factors for Chronic Diseases through Telephone Surveys (VIGITEL). Ministry of Health. Brasília, DF. Brazil, 2015. Available in: http://bvsms.saude.gov.br/bvs/publicacoes/vigitel_brasil_2014.pdf Accessed in: $10 / 5 / 2015$.

6. Blair SN, Dunn AL, Marcus BH, Carpenter RA, Jaret P. Active Living Every Day Champiagn: IL: Human Kinetics, 2010.

7. Scherer FC, Benedetti TRB. Health promotion programs: physical activity level and quality of life of old age in Health Centers of Florianópolis, SC, Brazil. (Master's Degree). Federal University of Santa Catarina. Florianópolis, 2014.

8. Bandura A, Azzi RG, Polidoro S. Social Cognitive Theory: basic concepts. Porto Alegre, Brazil: Artmed, 2008.

9. Brazil. Development Course on the Implementation of the National Policy for Health Promotion: Health Gym Program. Ministry of Health and Federal University of Santa Catarina. Brasília, Brazil, 2015. p.344.

\section{Corresponding}

Author

Tânia Rosane Bertoldo Benedetti

tania.benedetti@ufsc.br
Rua Mediterrâneo, 204, apto 501

Florianópolis, SC, Brazil

88034610

Telephone number: +55 483722379
Received 26/09/2016

Revised 18/01/2017

Approved 26/01/2017 